Agro-Science Journal of Tropical Agriculture, Food, Environment and Extension Volume 20 Number 4 (Special Issue, October 2021) pp. 8 - 21

ISSN 1119-7455

\title{
CLIMATE INFORMATION NEEDS AND SERVICES FOR CLIMATE CHANGE MITIGATION AND ADAPTATION IN CAMEROON, KENYA, MALAWI, NIGERIA AND TUNISIA
}

\author{
*Ozor N., Acheampong E. and Nyambane A. \\ African Technology Policy Studies Network (ATPS), $8^{\text {th }}$ Floor, Chancery Building, \\ Valley Road P.O. Box 10081-00100, Nairobi, Kenya \\ *Corresponding author: nozor@atpsnet.org
}

\begin{abstract}
Poor access and use of accurate, timely and appropriate climate information consistently to inform decision making in African countries pose a huge dilemma for sustainable development. The existing climate data observations networks coverage are sparsely distributed. Development strategies and plans are not adequately informed by climate science due to the limited reliable and useable climate data and information produced by National Meteorological and Hydrological Services and other relevant institutions. This paper describes the climate information needs of Cameroon, Kenya, Malawi, Nigeria and Tunisia, the status of the climate information systems (CISs), gaps and recommends improvement in the generation, processing and use of climate information. A study involving in-depth desk studies, key informant interviews, focus group discussions and policy dialogue was conducted. Results revealed that the CISs in the target countries have weak forecasting and alert systems for weather events and low capacities of stakeholders in climate prediction, development of climate products and information to support long-term planning, climate adaptation and resilience. The quality and appropriateness of data collected needs to be improved through networking, development and use of innovative technologies and capacity building. Institutionalizing climate data management training within climate data collection stations, creating modern real-time CISs by strengthening the capacities of national and regional institutions to use and disseminate climate information, is paramount. The capacity of the ministries involved in climate data management to deploy appropriate climate information and best practices to effectively implement climate-proof policies and practices should be enhanced to increase climate resilience and productivity.
\end{abstract}

Key words: climate information needs, climate service, adaptation, mitigation, capacity

\section{INTRODUCTION}

Despite having contributed the least to global warming and having the lowest emissions (about 7\%), Africa faces exponential collateral damage due to the low adaptation capacity and high exposure to climate extremes (African Development Bank, AfDB, 2019). It is a continent where the provision of seasonal climate predictions and multi-decadal climate projections remain challenging scientific tasks because of a mix of factors, including poor records of climate observations, poor simulation of interannual and decadal climate variability, and limited climate science investments. Several studies (Wheeler and Braun, 2013; Serdeczny et al., 2016) have concluded with a high level of confidence that the severity of the current and future impacts of climate change and the implications for Africa's economy will increase (Shongwe et al., 2009; Washington et al., 2013; Kusangaya et al., 2014; Vincent et al., 2015). Already, many African countries are witnessing severe climatic stress, manifested in high incidences of weather-related shocks, including drought, storms, flooding and extreme temperature (Thornton et al., 2014). The impact of these shocks on Africa's economy is further aggravated by the widespread poverty thus increasing the vulnerability of a large proportion of the population in many African countries.

The negative effect of climate change on social, economic and environmental systems have intensified the calls from various stakeholders, including development agencies, scientific institutions and civil society organizations to generate and deploy appropriate climate information in African countries (Jones et al., 2014; Vincent et al., 2015). This paper reiterates the continuous efforts by regional institutions such as the African Development Bank (AfDB), United Nations Economic Commission for Africa (UNECA), Africa Climate Policy Center (ACPC), and the African Union, among others toward establishing initiatives to support the delivery of appropriate and reliable data and information for climate services, policy-making and the development of best practices in African countries. A recent initiative is the Climate for Development in Africa Program (ClimDev) that was designed to overcome

Please cite as: Ozor N., Acheampong E. and Nyambane A. (2021). Climate information needs and services for climate change mitigation and adaptation in Cameroon, Kenya, Malawi, Nigeria and Tunisia. Agro-Science, 20 (4, Special Issue), 8-21. DOI: https://dx.doi.org/10.4314/as.v20i4.2 
the climate information gap by bridging the disconnection between climate service and development priorities through the establishment and maintenance of a continuous flow of climate information between producers and users in African countries (AfDB, 2013; ATPS, 2017). The initiative supports climate service providers and research institutions to generate, widely disseminate and effectively utilise climate information and services in African countries.

Despite the efforts at the regional level, there is a lack of access to consistent climate and weather information produced and packaged in formats that can be easily decoded and utilised to properly inform decision-making at the national and local levels (Singh et al., 2018). The density and coverage of existing climate data observations networks at the country level are generally described as poor and sparse (Parker et al., 2011). Development strategies and plans in African countries are not adequately informed by climate science due to the limited availability of reliable, useful and useable climate data and information produced by National Meteorological and Hydrological Services (NMHS) and research institutions. Climate information and data services are needed to inform decisions in the climate-sensitive sectors of national and local economies and to improve their resilience and adaptive capacity. This holds for African countries as stakeholders at the various levels must put in place robust mechanisms to strengthen their resilience capacity and to adapt to the impact of the changing climate. Strengthening the capacity of African countries to generate and effectively utilize climate predictions, products, and information services is critical for supporting long-term adaptation, planning and safeguarding the socio-economic development gains achieved at the local and national levels (Jones et al., 2015). Again, proper use of climate information could also potentially minimise the risk that decisions will adversely affect or increase the vulnerability of other systems, sectors or social groups.

The key question is: what are the appropriate climate information and data that could best equip African countries to face the growing threats of climate change? This paper attempts to answer this question by assessing the climate information needs in the five target countries, namely: Cameroon, Kenya, Malawi, Nigeria and Tunisia. While the institutional and landscape settings differ from one country to the other, these countries are representatives of the countries within their regions and share similar characteristics regarding the challenge of the availability and access to climate information and data services as well as the limited role of climate information in the decision making at the local and national levels. We, therefore, place the paper in the wider context of how climate information can inform adaptation planning, development policies and practices at the local and national levels in African countries.

\begin{abstract}
Objectives
The overall goal of this paper is to provide a deeper understanding of the specific climate information needs of selected countries as they plan their development agenda, build resilience and the adaptive capacity to climate change. Specifically, the paper seeks to (i) examine the climate information systems; (ii) Identify gaps in the generation, packaging, dissemination, access, utilization of climate information and services; (iii) examine the climate information needs of the key economic sectors namely agriculture, health, energy, transport, water resources, tourism, environment and natural resources; and (iv) examine the challenges and opportunities in the generation, processing and utilization of climate information for adaptation planning and resilience building in Cameroon, Kenya, Malawi, Nigeria and Tunisia.
\end{abstract}

\section{METHODOLOGY}

\section{Brief Characterization of Target Countries Cameroon}

With a land area of 475,650 km², Cameroon's 2019 population is estimated at 25.88 million, up substantially from the 2002 census population of 17.4 million according to the world population review report. This makes Cameroon the $54^{\text {th }}$ most populous country in the world and the $17^{\text {th }}$ most populous in Africa itself (World Population Review, 2021). Cameroon has five agro-ecological zones with varied landscapes and climates. These are described as Zone I (Soudano-Sahelian); Zone II (High Guinea Savannah); Zone III (Western Highlands); Zone IV (Humid Forest with mono-modal rainfall pattern); and Zone V (Humid Forest with bimodal rainfall pattern). Cameroon has a tropical climate with semi-arid conditions in the northern part, and the remaining part of the country being wet and humid. There is a huge variation in rainfall pattern with less than $600 \mathrm{~mm}$ of rainfall per year in the drier areas and over $3,000 \mathrm{~mm}$ of rainfall per year recorded in the coastal areas (INS, 2001).

\section{Kenya}

Kenya has a population of about 50 million people. The country is characterised by wide variation in the climate with conditions ranging from hot dry in the northern parts through cool and chilly conditions in the mountains and plateau to tropical warm and humid conditions in the coastal region. The average temperature in the coastal part is $27^{\circ} \mathrm{C}$. In the central part, the average annual temperature is estimated to be $19^{\circ} \mathrm{C}$ while the temperature in the northern part ranges from $21-27^{\circ} \mathrm{C}$.

\section{Malawi}

Malawi has an estimated population of 19.1 million as of 2020 (Government of Malawi, 2020). The country experiences a wet and warmer season with the highest annual precipitation (95\%) from 
November to April. Precipitation is dominant along the northern coast of Malawi with around 1,630 $\mathrm{mm}$ per year. This is pretty high because about $70 \%$ of the country averages between 750-1,000 $\mathrm{mm}$ precipitation annually. A variation in the amount of rainfall is in the range of 725-2,500 $\mathrm{mm}$. Between May and August, there is a relatively cool, dry winter season and temperatures fluctuate between $17-27^{\circ} \mathrm{C}$. Frost also occurs in some areas between June and July. Between September and October, there occurs a hot and dry season with temperatures fluctuating between $25-37^{\circ} \mathrm{C}$ and humidity is at $50 \%$. Between January and February, humidity is very high at $87 \%$ (DoDMA, 2015).

\section{Nigeria}

With a population of about 206 million, Nigeria accounts for $47 \%$ of West Africa's population (Millan et al., 2017; USAID, 2020). Nigeria has a tropical climate with semi-arid conditions in the northern part and progressively wetter conditions in the southern part of the country. Average annual precipitation varies according to the geographic region or the country. In the North-eastern part, the average annual precipitation is estimated to be approximately $500 \mathrm{~mm}$. In the central part of the country, the average annual precipitation ranges from 1,000-1,500 $\mathrm{mm}$ while the southern part has average annual precipitation ranging from 2,000$3,000 \mathrm{~mm}$. Temperatures vary widely in different parts of the country. The coastal region is characterised by an average of $32^{\circ} \mathrm{C}$ with high humidity. In the central part of the country, temperatures vary according to the different seasons. There are lower temperatures during the wet season from April to October with June being the wettest month. The dry season starts from November to March, with temperatures rising above $38^{\circ} \mathrm{C}$ during the day and dropping as low as $12^{\circ} \mathrm{C}$ at the night.

\section{Tunisia}

Tunisia is situated in the north of Africa with a total land coverage of approximately $164,000 \mathrm{~km}^{2}$. The climate is particularly arid and variable, with precipitation ranging from $800 \mathrm{~mm}$ per year in the north to $150 \mathrm{~mm}$ per year in the south of the country. In 2014, Tunisia's population was estimated to be 11.8 million (UNDP, 2020). The country has seen a steady decline in population rate, reaching an average of $1 \%$ over the past decade. Tunisia shares climate characteristics of the Mediterranean with hot, sunny summers and mild, rainy winter season at the northern coast. On the eastern coast, there is limited precipitation and even more limited precipitation on the south coast. The inland topography is either semi-desert or desert with very little precipitation and extreme temperatures of between $40-45^{\circ} \mathrm{C}$. Temperatures along the coast vary depending on the season, ranging from $16-18^{\circ} \mathrm{C}$ during winter and $32-33^{\circ} \mathrm{C}$ during the summer.

\section{Study Methodology}

The paper employed a mixed approach to data collection and analyses, drawing data from both primary and secondary sources. The first part of the research approach entailed a content analysis of scientific literature including peer-reviewed articles, research papers and review papers, grey literature such as policy documents, strategy and action plans, project reports, consultancy reports, donor reports and climate documentaries. Specific documentation accessed and reviewed from the target countries, including among others, national vision documents, national growth and development strategies, climate change and adaptation strategies and policies, nationally determined contributions (NDCs), national adaptation programme of action, climate investment plans, national environment policies and strategies, national disaster risk management policies and strategies, national health policies, national agricultural policies, national water policies, national tourism policies, urban policies and national energy policies. Implicit or explicit in all these documentations is the relevance of climate change as a causal element or a threat to the achievement of the goals and objectives stipulated in these documents. The rationale for employing the systematic analysis was to identify the kind of discourses around climate change and the kind of climate information that informed decisions in the target countries. The analysis was also conducted to identify the existing gaps in climate information generation and usage as well as the types of information required to address climate change issues in the target countries. The outcome of this analysis also informed the selection of key stakeholders who were engaged in the stakeholder dialogue at the learning platform.

Semi-structured and key informants interviews were conducted targeting government agencies and ministries (including national development planning commissions, environmental management agencies, meteorological services and ministries of environment and natural resources, agriculture, water, energy, transport and tourism), research institutions, civil society organizations, universities, international organizations such as United Nations Environment Programme and private companies involved in the generation of climate information and data services. Also, interviewed were climate information users including farmers, insurance companies, transporters and traders, etc. These interviews were conducted to interrogate the status and extent to which climate information informed the execution of the mandates of the various agencies, institutions and agencies and the rate of production and use of climate information and services in the target countries. Overall, a total of 39 interviews were conducted with 10 respondents coming from 
government agencies and ministries, 5 respondents from research institutions and universities, 4 from civil society organizations, 3 from international organizations, 2 from the private sector, 7 farmers and 8 respondents from the selected climaterelevant sectors, including agriculture, energy, transport, water resources, tourism, health, environment and natural resources. These sectors have been identified by actors in the target countries as sectors with great potential for maximum impact from the improved application of climate information and services. The interviews also informed the selection of the key actors for the regional stakeholder policy dialogue workshop.

The third aspect of the research approach entailed a three-day regional workshop and policy dialogue that targeted policymakers, scientists from research institutions and technical experts from meteorological departments, sector planning agencies, development agencies and civil society organizations. The regional workshop, which brought together 50 participants representing the different categories of key actors aimed at offering a platform for these important representatives to reflect on the usefulness of climate information services to the formulation and implementation of policies and plans in the identified sectors of the economies of the target countries. The two modes of engagement at the workshop were focus group discussions (FDGs) and participatory actor's dialogue. For the FDGs, participants were divided into 6 groups with each consisting of 8 individuals representing each of the selected sectors of the economy. Each group were tasked to assess the assigned sectors and identify relevant climate information that can support integrated climateproof development planning and policymaking. From this exercise, each group submitted a list of climate information needs required to contribute to decision making in the respective sectors as well as the dissemination pathways. The information was then organized and presented as case studies. Lessons, challenges and opportunities were drawn from the studies to inform future actions.

\section{RESULTS AND DISCUSSION}

\section{Analyses of the Climate Information System}

A climate information system entails the systematic collation, storage and processing of climate data from local, national, regional and global sources. In each target country, there exists a climate information system either established by the government or through a collaborative funded program or project. These functions of the climate information systems vary according to the level of sophistication and advancement, demand and usage of information for decision-making and operation and the relevance of climate information for climate adaptation and mitigation in the target countries. Common to all these countries, is a set of minimum priority functions, including the generation, mining and management of climate data; climate data analysis and monitoring; climate prediction (seasonal, annual, and decadal timescales); climate projections (multi-decadal and centennial timescales) and scenarios. These systems are also aimed at providing standardised structures and procedures for generating, retrieving, analysing, assessing, assimilating, and interpreting data and models for attribution and predications and projections furnished by a system of interlinked producers and providers of climate information (Trenberth et al., 2016).

Establishing a robust climate information system (CIS) is critical for the management of the complex flow of climate information from the sources and the delivery to the end-users. The successful generation and application of climate information and services at the different levels for decision-making is reliant on the establishment of robust and well-functioning climate information systems that draw on a wide range of information sources at different levels (national, regional, continental and global levels). In a functional climate information system, the fusion of historical climate data and near-time data provides reliable and quality products and services for the assessment of historical climate patterns, assist in making decisions on daily operations or facilitate actions that rely on climate information and services.

In order to successfully address climate change issues, African countries must have a robust climate information system that generates and processes high quality and reliable climate information that can inform mitigation and adaptation planning as well as development at various levels. In the target countries, stakeholders are working to establish functional climate information systems that can deliver value-added climate products and services that are accessible and tailored to user-specific needs. Below, the paper presents a brief analysis of the current climate information systems in Cameroon, Kenya, Malawi, Nigeria, and Tunisia.

\section{Climate information system in Cameroon}

Cameroon is still far from establishing a robust climate information system. The country has approximately 22 weather stations spread across the country that translates to $21,611 \mathrm{~km}^{2}$ per weather station. This severely affects the accuracy of data provided by the stations for areas that are more than a $5 \mathrm{~km}$ radius from the weather stations. However, according to the World Meteorological Organization (WMO), only 20 stations are enlisted. This could be probably because of the inability to collect weather information effectively to the acceptable standards set by WMO. Existing climate information was generated as part of the National Communication in Cameroon and include national 
relevant data from the initial studies of agriculture; livestock; fishing and aquaculture; forestry, silviculture and wildlife; water and sanitation; health; energy; mines; industries; public works; urban development; tourism, and also from the United Nations Development Programme (UNDP) studies in Cameroon. Experts started by studying the climate in each agro-ecological zone and compared it with past climatic data. The country is, however, making efforts towards establishing systems to enhance the production and dissemination of climate information. However, Cameroon does not have sufficient individual capacity to cope with this on its own. The situation is exacerbated by the reality that Cameroon remains one of the countries highly affected by climate extremes and climate change, and societal and economic vulnerability (WMO, 2008). Cameroon is a member of the WMO which consist of 188 members represented by their NMHSs. Technical experts in climatology, climate information service delivery and product development and transmission from the WMO are working with the NMHSs to establish mechanisms to improve institutional capacity for the generation of climate information, processing and usage. There is a qualitative and quantitative insufficiency of personnel in Cameroon in the required skills or competencies despite the effort of training and development of capacities started by the government with the support of development partners. Some training possibilities are offered at the national level. However, the structures available are in general not well equipped and the programs that are compatible with climate change or climate information services are not well developed or updated because of a qualitative and quantitative deficit of experts.

\section{Climate information system in Kenya}

Compared with several African countries, Kenya has a well-established system for the generation, process and use of climate information. The Kenya Meteorological Department (KMD) is a public institution mandated to provide meteorological, hydrological and related services in support of relevant national needs. Deriving its mandate from the WMO Convention, the KMD provides weather and climate information services at the national and county levels. It also undertakes research and development and education and training for various categories of stakeholders. The KMD operates thirty-six surface climate observing stations countrywide called Synoptic Stations, which provide information on rainfall, minimum and maximum temperatures, wind speed and direction, air pressure, soil temperature, solar radiation, sunshine duration, relative humidity, evaporation and cloud cover. Over three thousand rainfall stations are registered by the KMD and are operated by volunteer observers who mainly record rainfall data but some include temperature, however, this number is still small as the optimum recommended number is ten thousand. Twenty-four Automatic Weather Stations (AWSs) automatically record climate data and transmit it to receiving stations at the KMD. Most of these stations have enough long-term data to support climate trend analysis, however, care must be taken when using the volunteer stations due to concerns of not adhering to recommended standards for observation.

The KMD has decentralised climate information services through County Meteorological Office (CMO) with the goal to localise user-specific information at the county level. The CMO has the role of downscaling national-level products to address local needs. Weather and climate products include probabilistic weather forecasts, ranging from short-term (daily, weekly), medium-term (monthly) and long-term (seasonal and annual); rain onset, cessation and distribution; early warning advisories; and climate summaries and normal. The CMO uses historical climate data and local knowledge of climate variability to downscale the national monthly and seasonal forecasts to develop a forecast for the county and sub-county levels. In addition, the KMD has the Institute of Meteorological Training and Research (IMTR) which is one of the 23 WMO-Regional Meteorological Training Centre (RMTC) in the world. Together with the Department of Meteorology of the University of Nairobi and regional institutions such as the IGAD Prediction and Applications Centre (ICPAC), the IMTR conduct research and development and training on matters pertaining to meteorology and climate information services in Kenya and East African countries.

Efforts to bridge climate service gaps in Kenya has brought on board several groups and agencies, and these include research and academic institutions; non-governmental organization (NGOs); governmental agencies; private sector; and regional and international organizations who play an active role in the context of CIS. In collaboration with KMD, regional climate centres such as the Intergovernmental Authority on Development Climate Prediction and Applications Centre (ICPAC) and the African Centre of Meteorological Applications for Development (ACMAD) work to generate climate information for stakeholders within the region. Some of the CIS providers act as both users and producers of climate information especially those whose work revolves around community engagement and development (World Bank Group [WBG], 2016). The KMD has a diverse array of human resources specialised and focused on various aspects of climate information services provision. However, with the transition to a decentralised climate information system to the county level, and with 47 counties to be covered across the nation, this has created a challenge in the 
availability of human resources at the county levels, with many of the county offices not having an adequate number of employees recommended for the provision of climate services.

There is the need to train climate information system intermediaries on methods of application and generation and dissemination of user-oriented climate information; and also to train volunteer observers and county climate officers on appropriate methods and techniques for collecting and disseminating climate data and information. Human capacity has to be developed in such areas as the systematic observations of climate change using the existing national and county networks including volunteer observers and community data monitors. With demands rising for climate information, there is need to acquire new technologies for climate data acquisition, monitoring, analysis and modelling, and dissemination and user outreach. This also comes from the rise of such new technologies as Smart Agriculture Initiatives which require specialised information. Therefore, there is need to develop knowledge on climate change-related issues, develop urban emission inventories, and carry out urban climate studies, air pollution modelling, monitoring and forecasting.

\section{Climate information system in Malawi}

The development of an effective climate information system in Malawi dated back to the mid-1940s when the Meteorological Department (now the Department of Climate Change and Meteorological Services) established a systematic network of stations to generate weather information mainly to support the aviation services. Following the establishment of few stations to address the aviation service needs, the need to establish more meteorological stations to generate more information for other sectoral needs became apparent. The current network of stations consists of 22 meteorological stations and 21 subsidiary agrometeorological stations that are strategically positioned in the eight Agricultural Development Districts (ADDs). In the past few years, the Department of Climate Change and Meteorological Services has established several stations to provide information for development projects in agriculture, forestry, water resources, fisheries, wildlife, education, etc. The department is the sole institution mandated to monitor, forecast and provide information on weather, climate and climate change in the country. Malawi recognizes and appreciates the need for technology development and transfer for the generation and processing of climate information and services. However, financial resources for addressing the identified needs such as the development of climate change research agenda and enabling environment for the application of science and technology are inadequate (GOM, 2016).
Within the climate information system, Malawi has few specialised trained staff in climate change management and specialised training programmes are not available in local universities. Primary and secondary school education curricula are still devoid of climate change content. This is affecting programming efforts at the national level as there is limited expertise to design and implement serious climate change programs, which usually require high levels of technical expertise. However, the Government of Malawi through the Ministry of Environment and Climate Change Management, academic institutions and NGOs have conducted several training sessions for Members of Parliament (MPs), the Technical Committee on Climate Change (TCCC), and the local communities aimed at building capacity on climate change issues. Through the Africa Adaptation Programme (AAP), the Malawi Government has trained 10 professionals at Master of Science degree level in climate change.

\section{Climate information system in Nigeria}

Within the climate information system, the Nigeria Meteorological Agency (NIMET) represents the national centre for climate data and information collection, policies and guidelines on climatic and meteorological services. The Agency has 54 ground meteorological stations that serve as data observation and collection points in the country. The meteorological information is collected regularly at each station and transmitted directly to the national centre of data collection. At the national centre where all the data converge, some experts control the quality of the data which are stored in a databank through a database management system. These data are used for weather forecast, climate forecast (e.g., seasonal forecast,) and climate change and variabi-lities predictions depending on the timescale. The same data collected can be used in models to make predictions or evaluate the impact of the climate on some socio-economic activities. The NIMET has the technical infra-structure and capacity to deliver the products to users but need more capacity building to tailor the products. Current dissemination and communication strategies of the climate and weather information are done periodically through a couple of days, weekly, monthly to seasonal and yearly basis via $\mathrm{TV}$, website and a mailing list.

In order to achieve its mandate, NIMET is structured into different directorates including administration and supply, applied meteorological services, engineering and technical services, finance and accounts, legal services, research and training, weather forecasting services. Most of the technical works and services delivered to different users are done by applied meteorological services, engineering and technical services, research and training and weather forecasting services. The 
Directorate of weather forecasting services is responsible for the generation of weather data and information and accurate forecast for navigational safety. It also provides forecasts for search and rescue to aid the activities of the Accident Investigation Bureau (AIB) of the Aviation Ministry and the National Emergency Management Agency (NEMA) during disasters. The Directorate of Applied Meteorological Services (DAMS) is one of the operational sub-systems of NIMET. Three Divisions make up the Directorate of Applied Meteorological Services via Agrometeorology, Hydrometeorology and Marine Meteorology Divisions. The Directorate is also in charge of NIMET's Remote Sensing and Geographic Information Centre. The collection of data, and production of climate services, the agency uses facilities and technical experts situated at the headquarters in Abuja Airport, and regional offices in the Federal States.

\section{Climate information system in Tunisia}

Tunisia is among the African countries with an advanced climate information system. The National Institute of Meteorology (NIM-INM) has the mandate to provide weather and climate information services to support the needs of the various sectors in Tunisia's economy. The NIM activities are mainly focused on Meteorology and Geophysics. Regarding meteorology, the NIM has the full skill and ability to perform- data collection, processing and, exchange; weather forecasting; climatology and applied meteorology (Agro-meteorology and Hydrometeorology). Regarding activities dealing with Geophysics and Astronomy, NIM ensures- the measurement of seismic activity, applied geophysical studies; observation of the lunar crescent, eclipse and lunar calendar elaboration; and measurement and processing of different types of solar radiation. The data are stored in a database and disseminated in different formats to end-users which are the main interfaces with the national authorities in charge of decision making in different sectors (Health, Agriculture, Environment management, civil aviation, etc. In addition to data generation and dissemination, NIM provides capacity building to end-users in order to know, understand and better exploit climate data available to them. Free validated public data can directly be accessed through the website of NIM as well as other national institutions that gather and use information/data in various formats from diverse sources.

Despite the growing knowledge base built and managed by NIM (the National Weather Service), the other, technical, important information and knowledge gaps still need to be filled. These may be related among others to the non-availability of the more precise downscaled local level dataset; poorly established national climate modelling and forecasting services at the NIM; low capacities of the stakeholders (government agencies, climatesensitive sectors such as agriculture, energy, tourism and transport) in the mastering and use of climate predictions, products and information to support long-term planning on adaptation; the difficulties in publishing the results of research originates from NIM; and the lack of portable technologies for the collection and processing of climate information at the local level. The NIM maintains good cooperation with the National Center for Meteorological Research (CNRM) of METEO-France, in terms of equipment, since 2004, NIM has acquired a super calculator which, since 2013, has been equipped with a high-resolution model coupled version ARPEGE-CLIMAT. Besides, the NIM represents an important node on Climate Monitoring and Watch for the North Africa Regional Climate Centre Network (RCC-RA I). In collaboration with RCC-RA I, the NIM is now providing some basic climate diagnostics including analysis of climate variability and extremes such as drought.

\section{Climate Information Gaps}

One of the greatest challenges in responding to climate change is how to pin down the information needed to understand the risks and plan effective measures to address them. Despite the fragmented nature of climate data collection in the study countries, it became evident that the current volume of available information is massive. Sorting through these documentations and identifying the specific requisite information to address the questions being posed may be beyond the capacities and resources available to both experts and decision-makers in the study countries. There are significant gaps between the questions posed by decision-makers and the answers available. From the discussions held with key stakeholders, all the study countries experience gaps - in the integration of climate information into national policies; in the incorporation of climate information into practice at scale; and in existing climate data and services. The lack of a holistic or integrated approach and long-term support for weather and climate services hinders the use of climate information, particularly at the local scale. According to the WMO, there are several critical gaps in the process of climate information generation, processing and dissemination in all the study countries. These include - deficiencies in atmospheric observations due to the inability to maintain networks, inadequate communications systems; lack of training and capacity development; incomplete or missing observations of vital landsurface parameters such as river discharge and lake levels; restrictive data policies and ineffective information infrastructures; and the need to rescue, digitize and develop historical climate data sets (WMO, 2014). The review of the existing gaps suggests that the NMHS in all the study countries require some form of modernization following a long period of underfunding, poor maintenance and perceived irrelevance due to low visibility. 


\section{Climate Information Needs across Sectors}

Several sectors are sensitive to climate change impacts. The UNDP identified eight climatesensitive sectors namely: agriculture, livestock, fishery and aquaculture; biodiversity; water; energy and mining; industry; sanitation and health; urban development and public works, and human development (UNDP, 2011). In the analyses of climate information needs, this paper considers seven of the eight sectors for their relevance to the study. They include; agriculture and food security, health, energy, transport, tourism, water resources and environment and natural resources.

\section{Agriculture and food security}

Climate information and data services for the agriculture and food security sector remain a critical concern for the majority of providers and users in all the target countries. Agricultural users of weather and climate services typically require weather and climate products on a combination of timescales, including historical observations, monitored information throughout a growing season, daily/weekly weather forecasts, monthly outlooks, seasonal predictions, and decadal climate change projections (Tall et al., 2014). Such information supports the planning of the agricultural calendar as well as putting in place sustainable management practices to cope with unfavourable climatic events. From the interviews conducted in all the target countries, the study identified several needs that were prevalent in all the countries. These include the need to:

- develop tools for downscaling of climate information to produce local information and forecasts;

- develop tailored forecasts to meet user needs, including the use of local languages and a wide range of communication channels;

- provide simple weather and hydrological monitoring equipment to local communities to raise awareness, promote dialogue and data exchange;

- combine local knowledge with climate information derived from the meteorological services to support decision making at the local level; and

- strengthen the integration of global and regional climate information systems with wider national frameworks and plans.

In addition to these, the study identified country-specific climate information needs. For example, in Cameroon, it was evident that the weak institutional framework and inadequate infrastructure hindered the generation, processing and dissemination of climate information for use in the agricultural sector. In Malawi, the Vulnerability Assessment Committee (VAC) that monitors food security only looks ahead to the coming season, and therefore decisions are currently based on observations, rather than modelling or projections. In effect, current planning and decision-making are based not on model projections but rather on linear regression of past averages - observations from the past are used to predict future events. Such linear modelling, which is also used by other ministries such as the Ministry of Agriculture and Food Security (MoAFS) and Ministry of Irrigation and Water Development (MoIWD) is potentially problematic as it assumes that the future will mirror the past, which may not be the case under projected climate change (Vincent et al., 2014). In Nigeria, there is a growing need for the timely generation and dissemination of information on climate and weather for people whose livelihoods are mostly affected including rainfall intensity forecast, drought forecast as well as crop yield forecast and the potential areas at risk. There are several calls for the review of the current curriculum for training prospective agricultural extension officers to incorporate specific climate information needed for adaptation to climate change. Another critical need is the development of capacity building programmes that are relevant to the relationship between climate change and agricultural production for appropriate ministries, agencies and departments (MDAs) at all levels.

\section{Health sector}

Weather and climate conditions on all timescales have both direct and indirect effects on public health and safety through extreme events such as heat waves, floods and droughts, as well as the prevalence and severity of infectious, vector- and water-borne diseases such as meningitis, malaria, and diarrhoea (WMO, 2014) and cholera (De Magny et al., 2007). In all the target countries, rapid urbanisation with a lack of modern drainage systems and wastewater systems has the potential for increasing the prevalence of water-borne diseases. While there is significant relevance of weather and climate on public health in all the study countries, the generation, uptake and application of climate information and services to inform policy and strategies within the health sector are relatively low. This could be attributed to factors, including low capacity to effectively understand and apply climate services in the health sector; lack of capacity to manage and monitor the risks of climate variability and change on public health; lack of access to the relevant climate datasets; and an institutional disconnect between the public health community and other sectors which consider public health as a downstream priority such as food security and water resource management (Jancloes et al., 2014; WMO, 2014). In all the target countries, the existence of weak disease control and climate surveillance and reporting systems hinder the collection and analysis of long-term data sets on climate and disease prevalence required for developing early warning systems. Some countries have already taken steps to address climate information needs. For example, 
in Kenya, there exist strong national-level partnerships between the climate and health communities through the Climate and Health Working Groups (CHWGs) that target research, education and data exchange to improve service delivery and increase the capacity of NMHSs (Rogers et al., 2014). However, according to Connor et al. (2010), some limitations exist in the development of decision-support tools relevant to the health sector, and the collaborative development of weather and climate advisory services for practical use in the health community. Tunisia has an approved national health adaptation strategy and has conducted a national assessment of climate change impacts, vulnerability and adaptation for health. Additionally, there is an established setup for the development of institutional and technical capacities to work on climate change and health.

\section{Energy}

The generation of energy for economic growth and societal development, in general, is significantly affected by climatic events. Although this is certainly the case for renewable sources such as wind, solar and hydropower and electrical distribution and transmission systems, the more traditional energy sources can also be severely impacted by extreme weather and climate events. Thus, by properly taking into account weather and climate information, energy systems can considerably improve their resilience to weather extremes, climate variability and change. The main energy source in all the target countries is mainly hydroelectric power. The impact of climate change on hydroelectric power generation in these countries has been manifested by droughts and floods over the past years. Some of the target countries have been experiencing power shortages associated with recurrent droughts. The risk of serious power shortages and the resultant slowdown of economic growth rate will be even higher as droughts increase in frequency and intensity.

Data from Nigeria suggest that only the seasonal rainfall forecasts are provided to the energy sector. There is an expressed need for the energy sector to have information on rainfall intensity forecast and the drought forecast. For oil and gas fields, NIMET supplies tailored weather forecasts in both terrestrial and offshore environments to support risk management and daily operations. There is a strong need for forecast on extreme weather events, and accurate estimation of highly risky climatic events. Cameroon has also recently conducted studies to generate data on its solar and wind energy potential. The results show that the northern region has high solar potential while there is a high potential for wind energy in the West. The country is preparing a renewable energy policy to explore the potential of renewable energy, mainly solar and wind as supplements to hydropower given that low energy supply represents a major hindrance to Cameroon's pathway towards economic growth according to the Minister of Water and Energy Resources. In Kenya, the Kenya Electricity Generating Company (KENGEN) has collaborated with Kenya Meteorological Department to apply the use of climate knowledge especially for energy planning at seasonal and for long-term implementation in the hydroelectric power plants. Climate information has also been useful in the planning and installation of wind and solar energy plants. However, the lack of such datasets as wind and solar energy creates a challenge in the application of such green sources of energy. The application of renewable energy for climate change mitigation and the need for planning of energy generation will continue to require climate information, especially on hydrological fluctuations, wind, and solar viability, and also on risks such as storm and lightning surges.

\section{Transport}

Extreme weather events and climate change and variations can affect transport systems and have significant impacts on society. Stakeholders agreed that extreme weather events such as heavy storms, winds, floods, and drought have immediate effects on day-to-day operations, often disrupting large portions of a transportation network in all the target countries. Expected climate change and variations, such as increasing temperatures, intense hurricanes and precipitation events, and rising sea levels, have long-term impacts on all aspects of transportation. In order to develop appropriate planning, response, and adaptation strategies, it is important to have information on how weather and climate trends affect the various modes of transportation. For instance, in Nigeria, NIMET offers weather services and report to aviation to improve the safety and efficiency of air navigation by assisting pilots with some tailored products, including the Terminal Aerodrome Forecast (TAF), en-route and destination weather forecasts and trends; briefings for pilots and airmen on expected weather at various points; routes with the clock weather report of points of departure, en-route and destination by radio transmission; and significant weather reports (SIGMET), which is a vital tool for flight routing during movements, etc. For marine operations, NIMET provides oceanographic information for marine users both at sea and along the coast. This makes the decision-making process during weather sentinel operations more efficient.

\section{Water resources}

The use of climate services in the management of water will require defining relevant climate services, including climate prediction products, seasonal climate, outlooks, downscaling products at various levels and different downscaling 
methodologies. For water resources management, climate and hydrological data are important in the estimation of the resource potential, sustainable yields and allocation of resources through licensing or permitting at the catchment scale. In the application of climate information for integrated water resource management in the study countries, the majority of stakeholders expressed the need for:

- a stronger enabling environment that supports capacity building and collaboration in water management at international, regional and national levels;

- building national capacity in national hydrometeorological services from data observation and retrieval;

- developing the necessary tools that allow easy access of climate information by users;

- improving the hydro-meteorological monitoring network and climate data collection, exchange and management;

- employing IT infrastructure to support remote access to climate data; and

- enhancing the application of satellite observation data and application of modern technology to improve water resources management.

Extreme climatic events such as floods and drought affect water availability in all the study countries. In the development of sustainable water management plans, the incorporation of climatic information is instrumental in defining the appropriate strategies to address diverse issues, including water scarcity, flooding and drought, etc. For instance, Kenya has already made many efforts in the development of integrated water resource management, with information on flood and drought early warning being provided by KMD. In Nigeria, seasonal rainfall prediction, flood and drought information are produced for environmental and natural resources managers at all-time scales but there are gaps in the area of rainfall intensity and drought forecast.

\section{Tourism}

Even though most tourism demand studies focus on economic variables, climate is regarded as a key driver for tourism and an important attribute of a destination (Crouch, 1994; Lim et al., 2008). In some cases, climate serves as the main tourism resource, for example in the case of beach destinations (Kozak et al., 2008), or it acts as a facilitator that makes tourism activities possible and enjoyable. Studies show that besides destination choice, climate is also an important factor for the timing of travel (Lohmann and Kaim, 1999; Hamilton and Lau, 2005). Seasonality has been described as one of the main challenges of tourism's viability. Tourism's seasonality is not only driven by climatic conditions at the destination and tourists' home countries, but also by institutional factors such as school holidays
(Butler, 2001). There has been a longstanding desire to capture or assess the climatic suitability of a potential or existing tourist destination. Factors that seem to be important include climatic elements such as temperature, wind chill effects, humidity and radiation. Other measures, such as wind speed or snow depth may also be important for specific recreational activities. The climatic parameters can be aggregated to a single index that gives some indication of a place's suitability for specific touristic activities. Given the importance of climate to tourists in making decisions as well as holiday experience, it is expected that tourists would actively seek climatic information. Such kind of information would be particularly valuable in areas where the weather could pose significant health and safety risk for tourists, for example in hot destinations or tropical zones. Different types of information are required at different stages of the trip planning process. In Tunisia, tourism destinations are mainly the beaches and seaside resorts, which means that it is particularly sensitive to the summer climate, rising sea levels and coastal erosion. The temperature rise will make the heat in summer more severe, affecting humans' climate comfort and making heat waves unbearable for the human body. Access to regular climate information is very essential to both tourists and managers of tourist destinations. Kenya has one of the best climatic conditions throughout the year. However, access to daily, monthly, seasonal and annual climatic information is highly essential to monitor any extreme events such as cold, floods, heat, and excessive rainfall that can impede the development of the tourism industry.

\section{Environment and natural resources}

Weather and climate influence our environment every day, every season, every year. One extreme weather event can affect wildlife or habitats for many years. The adverse effects of climatic change to the target countries are already exerting considerable stress on the environment and natural resources from which revenue for development is generated such as exploitation of natural resources. This poses a serious threat to national development and poverty reduction. Generating and using climate information is crucial for environmental and natural resource managers in their effort to address the impact of extreme climatic events. From the focus group discussions conducted, it became evident that there is a growing need for reliable climatic information that can support the assessment of risks and opportunities for environmental and natural resources management. For instance, in Tunisia, environmentalists and resource managers may require critical details into how increased temperatures may influence the rise in the flammability of biomass and risk the rise of wildfires and forest loss. 
Challenges in Collection, Analysis and Dissemination of Climate Information and Services One of the greatest challenges in responding to climate change impacts is how to pin down the information needed to understand the climate risks and plan effective measures to address them. The user needs for climate information vary and are very dynamic. It is not a situation of one size fits all in especially for most countries. The sectors of concern for the majority of CIS providers vary and are focused on agriculture and livestock, water and water resources, financial/planning, environment and natural resources, energy, research and development, health, media, construction/ infrastructure, and disaster management (WBG, 2016). The study identified the following common challenges that confront the process of collecting, analysing and disseminating climate information and services in the study countries.

\section{Lack of sophisticated climate tools}

The lack of technical and computing facilities at the various agencies hinder the application of technologies and equipment which would improve the generation and access to climate information. Climate tools are also not available for local scales and especially for climate downscaling purposes. Some of the technologies including satellite-based systems are in limited use by providers due to lack of technical capacity to apply them.

\section{Quality of climate information services}

Many actors in the climate information system environment are offering various climate information services and products. However, a key challenge for most of the study countries is the lack of a common framework for sharing of information or procedures of operation directly defining the generation of user-oriented climate information products. This hinders the process of review of climate products and services products to define and justify quality.

\section{Appropriateness of scale}

Different climate users have different information needs and these vary in temporal, spatial and even in form. The need to decentralise climate information to the county or local government and state or provincial levels has triggered diverse demand for climate services that are appropriate for user-level decision-making. Although the national or federal level products are expected to be downscaled to the local, county or state levels, these different levels create demand for unique products some of which need to be regenerated and custom-made. The tools to support such downscaling and the procedures are also not well developed and documented.

\section{Communication}

The diversity of user needs in the country, and also the differences in culture, language, and literacy levels are key challenges in the development and communication of climate information. These are compounded by lack of the right technology which allows for equal access to information to all who need it. Most climate information comes in a form that might not be readily applied for user-level decision-making either because they are technical or the methods of dissemination become a challenge thereby hindering accessibility and applicability.

\section{Interpretation}

The application of climate information requires an understanding of both the technical aspect of the information and the applicative needs of the users. This requires the effort of interpreters who understand the technical aspect of the content of the climate information and also the user applicative needs. However, this is usually not the case, mainly because some of the CIS come in technical language, or may not be having the right content or form recommended for applicability.

\section{CONCLUSION}

Given the critical role of climate in our society, the generation, processing and application of appropriate climate information will help prevent the economic setbacks and humanitarian disasters that can result from climate extremes and long-term climate change. In this paper, we delved into the climate information systems in five countries, namely: Cameroon, Kenya, Malawi, Nigeria and Tunisia to understand the climate information needs in the key sectors of the economy while identifying the gaps, challenges and opportunities in the generation, processing and utilisation of climate information for adaptation planning and development in these countries. Results from the study showed that the selected countries have all established climate information systems with institutions mandated to oversee the operations of the systems. The level of sophistication of the climate information in each country varies depending on the advancement of the countries under study. Of the five countries, the climate information system of Tunisia, Kenya and Nigeria could be described as well-established with good degrees of institutional, technical, human, and collaborative capacities to generate, process and disseminate climate information. Although Cameroon and Malawi have established climate information systems, these systems lack the capacity to generate the requisite climate information for the country due to lack of investments and a generally low level of technical expertise able to support climate monitoring networks and climate data processing and utilization. As a result of these problems, government institutions, developmental practitioners and service providers engaged in climate-sensitive sectors of the economy are rarely oriented to plan 
or manage climate risks. In Cameroon for instance, there are only 22-24 functioning weather stations with only 20 submitting weather readings to WMO. The funding for the provision of climate services by the government is very low and this has exacerbated the ability of users to access quality climate information and products.

Climate information has not been used effectively wherever and whenever it is available in many of the African countries. This is partly because of the low capacity to collect, interpret and package it usefully for use by various users such as farmers, conservationists or policymakers. This has therefore led to the low appreciation of the value of the information generated in the various weather stations in the country. Various sectors in the countries continue to suffer from risks that could have been prevented or mitigated if the people responsible had the climate information packaged usefully and on time. There are a few instances where the countries are beginning to put information into valuable use in a few sectors such as agriculture, conservation and tourism. In Tourism for instance, short to medium range forecasts are used to advise visitors on the best days or periods to visit particular tourist attraction sites. Up-to-date data that is critical for climate change analysis and information dissemination, as well as for improving the understanding of climate problems in the context of sustainable national development, is not readily available in several countries in a coherent and accessible manner. There is, therefore, need to reinforce countries' efforts at putting in place a comprehensive climate change information management system that is updated periodically and readily accessible to the end-users.

In the study countries, stakeholders are fully aware of the impact of climate change on socioeconomic development, natural resources and the need for climate information. There are various challenges caused by limited technical capacity, human resource needs, financial challenges, and a limited operating environment for climate information system provisions. These challenges hinder the provision of climate information, especially at the grassroots and level. These challenges should be overcome, but most of all, a framework for the collaboration and integration of climate information systems needs to be established to properly coordinate climate information services within the countries. These countries need to adopt a more comprehensive and coordinated approach to the issues of climate change within their national development context than what currently exists. There is an increasing need to collect high-quality climate information, analysis and packaging into products that target specific users and disseminated using appropriate channels such as the agricultural extension agents so as to reach the target users promptly in order to make timely decisions.
However, for this to happen, countries have to invest in modern efficient technologies, recruit and train staff on how to use the upgraded technologies and how to package and disseminate the information to make sense for the end-users. To achieve all these, it will be important and necessary for governments to partner with the private sector as well as solicit support from donors, and collaborate with researchers and other stakeholders.

\section{RECOMMENDATIONS}

At the first African Ministerial Conference on Meteorology (AMCOMET) held in Nairobi between 12-16 April 2010 assembled 500 policymakers from all African countries to deliberate on the improvement of climate information and services, it became evident that African countries recognised the critical importance of generating reliable and valuable climate information for appropriate decision-making. Out of the experiences gathered from the five study countries, this paper provides five key recommendations that would support the aim to improve the generation, processing and use of appropriate climate information to address the specific needs of targeted end-users.

\section{Improve technical, technological and institutional capacity}

Institutional reforms are needed in the NMHSs to enable them to adjust to the new demand for data and information on climate as a result of the growing threat posed by the changing climate. There is need to increase capacity to use satellite products and also the need for strengthening capacity in climate modelling, application of modern monitoring technology including maintenance of equipment, quality control of data and calibration of facilities. The capacity to apply information communication technology and all possible avenues for communication, transmission and dissemination of climate information should be improved. This should focus on the provision of a user interface that can allow for feedback process and encourage interaction between and among relevant stakeholders in the sectors. Agricultural extension agents will specifically play important role in the communication, use and dissemination of CIS targeting farmers and farmer groups in rural areas in order to build their resilience capacity for increased agricultural productivity.

\section{Improve coordination of CIS provision}

An effective service delivery strategy should be established that includes a platform that provides forecasts of the weather's impact based on information available from numerical weather predictions, observations, and risk assessments, and user-specific products. The platform can include a web-based information portal for climate service providers, service and product portfolios including 
methods of generation, and encouragement of continuous interaction of various stakeholders and users. A formal framework that will allow networking of CIS providers and key stakeholders, and the provision of standard operation procedures for products generation and dissemination. An approach to protect data ownership and equally eliminate barriers for effective exploitation of climate information is recommended.

\section{Establish climate information service quality management system}

At present there is no framework for the evaluation of climate services and climate information content at the various levels in most of the study countries, making it difficult for users to identify high-quality climate services. An accreditation and quality management system geared towards appropriate definition of climate services, setting standards, labelling, and validation is required. Standard procedures for evaluating climate data and products should be established. An effective and interactive user feedback mechanism should also be put in place to provide an avenue for the evaluation and improvement of climate information products and services.

Foster partnerships of climate information systems There is a greater need to collaborate in the production and generation of climate information products especially in co-designing of climate products with end-users and providers, and to bridge the gap in the provision of climate information. Promoting the adoption of effective climate information and services will require well-designed, inclusive, and innovative systems with clear quality checks and balances. This will result in more robust CIS systems and user-led approaches. The use of colearning and co-management strategies involving providers and users should be encouraged. Transdisciplinary research on weather and climate services can enhance CIS knowledge integration.

\section{Public-Private Partnerships (PPPs) for climate information systems}

Developing advanced partnerships between the government and private sector is a solution where government investment in meteorological services is likely to remain a small part of overall spending. National consortia involving a wide group of stakeholders with mutual interests in weather and climate information can collectively fund, maintain and utilise observing networks. However, a framework is needed to ensure that all socially relevant information is exchanged freely and remains freely available in the public interest. The top priority for improvement in weather and climate services is the optimisation and integration of the observation, modelling, and prediction system with a special focus on improved observations of water and other key variables.

\section{REFERENCES}

AfDB (2019). Climate change in Africa. COP 25. Blog. Available at: https://www.afdb.org/en/cop25/climatechange-africa

African Development Bank [AfDB] (2013). Africa on the Rise: Can the Opportunities from Climate Change Spring the Continent to Transformative Development? Third Conference on Climate Change and Development in Africa (CCDA-III) 21-23 October

African Technology Policy Studies Network [ATPS], (2017). Bridging Climate Information Gaps to Strengthen Capacities for Climate Informed Decision-making: Project Launch Proceedings, African Technology Policy Studies Network (ATPS). Available at: https://atpsnet.org/wpcontent/uploads/2017/11/ATPS_ProceedingsReport_Project_Launch_Sept-2017.pdf

Butler R. (2001). Seasonality in tourism: Issues and implications. In: Baum T. and Lundtorp S. (eds.), Seasonality in Tourism (pp. 5-22). London, Pergamon

Connor S., Omumbo J., Green C. et al. (2010). Health and climate needs. Proc. Environ. Sci., 1, 27-36

Crouch G.I. (1994). The study of international tourism demand: A survey of practice. J. Travel Res., 32 (4), 41-55

De Magny G., Guégan J., Petit M. and Cazelles B. (2007). Regional-scale climate-variability synchrony of cholera epidemics in West Africa. BMC Infect. Dis., 7 (1), 20

DoDMA [Department of Disaster Management Affairs]. (2015). Malawi Hazards and Vulnerability Atlas.

Government of Malawi [GOM]. (2020). Malawi Country Operational Plan 2020: Strategic Direction Summary. Lilongwe: U.S President's Emergency Plan for AIDS Relief

Hamilton J. and Lau M. (2005). The role of climate information in tourist destination choice decisionmaking. In: Gössling S. and Hall C.M. (eds.), Tourism and Global Environmental Change (pp. 229-250). London, Routledge

INS [National Institute of Statistics]. (2001). Poverty and health in Cameroon in 2000. Yaoundé

Jancloes M., Thomson M., Costa M. et al. (2014). Climate services to improve public heath. Int. J. Environ. Res. Public Health, 11, 4555-4559

Jones L., Carabine E., Roux P. and Tanner T. (2015). Promoting the use of climate information to achieve long-term development objectives in sub-Saharan Africa: Results from the future climate for Africa scoping phase. Retrieved from: https://cdkn.org/wpcontent/uploads/2015/02/CDKN_FCFA_synthesis.pdf

Jones L., Roux J., Scott C. and Tanner T. (2014). Background briefing: Opportunities and barriers to the uptake of long-term climate information in African decision-making (Future climate for Africa/CDKN report). London: Overseas Development Institute

Kozak N., Uysal M. and Birkan I. (2008). An analysis of cities based on tourism supply and climatic conditions in Turkey. Tour. Geogr., 10 (1), 81-97

Kusangaya S., Warburton M., Van Garderen E. and Jewitt G.P. (2014). Impacts of climate change on water resources in southern Africa: A review. Phys. Chem. Earth, 67, 47-54

Lim C., Min J. and McAleer M. (2008). Modelling income effects on long and short haul international travel from Japan. Tour. Manag., 29 (6), 1099-1109 
Lohmann M. and Kaim E. (1999). Weather and holiday preference - image, attitude and experience. Revue de Tourisme, 2, 54-64

Millan M., Rodrick D. and Sepulveda C. (2017). Structural change, fundamentals, and growth: A framework and case studies. Policy Research

Parker D., Good E. and Chadwick R. (2011). Reviews of Observational Data Available over Africa for Monitoring, Attribution and Forecast Evaluation, Feb. 2011 - revised Jun 2011, Hadley Centre Technical Note 86

Rogers D.P. and Tsirkunov V.V. (2014). Weather and Climate Resilience Effective Preparedness through National Meteorological and Hydrological Services. World Bank

Serdeczny O., Adams F., Baarsch D. et al. (2016). Climate change impacts in Sub-Saharan Africa: from physical changes to their social repercussions. Reg. Environ. Change. DOI: 10.1007/s10113-015-0910-2

Shongwe M., Van Oldenborgh G., Van Den Hurk B. et al. (2009). Projected changes in mean and extreme precipitation in Africa under global warming, Part I: Southern Africa. J. Climate, 22 (13), 3819-3837

Singh C., Daron J., Bazaa A. et al. (2018). The utility of weather and climate information for adaptation decision-making: current uses and future prospects in Africa and India. Climate Dev., 10 (5), 1-17

Tall A., Hansen J., Jay A. et al. (2014). Scaling up climate services for farmers: Mission Possible. Learning from good practice in Africa and South Asia (CCAFS Report No. 13; Copenhagen, Denmark: CGIAR Res. Prog. on Climate Change, Agric. \& Food Security CCAFS)

Thornton P.K., Ericksen P.J., Herrero M. and Challinor A. (2014). Climate variability and vulnerability to climate change: a review. Glob. Change Biol., 20 (11), 3313-3328

Trenberth K., Fasullo J., Von Schuckmann K. and Cheng L. (2016). Insights into Earth's energy imbalance from multiple sources. J. Climate, 29 (20), 7495-7505

United Nations Development Programme [UNDP]. (2011). Integrated and Comprehensive Approaches to Adaptation to Climate Change (CCAP) Stakeholder analysis and assessment of climate change adaptation capacity assessments of key climate change institutions in Cameroon. Launch document for study implementation report. UNDP Yaoundé-Cameroon
UNDP (2020). The Next Frontier: Human Development and the Anthropocene Report. Tunis: UNDP

USAID [United States Agency for International Development]. (2020). Nigeria: Nutrition Profile. Lagos: USAID

Vincent K., Dougill A.J., Dixon J. et al. (2014). Actual and potential weather and climate information needs for development planning in Malawi: Results of a future climate for Africa pilot case study. Future Climate for Africa Pilot Case Studies. Retrieved from http://cdkn.org/resource/climate-informationdecision-makingmalawi

Vincent L.A., Zhang X., Brown R.D. et al. (2015). Observed trends in Canada's climate and influence of low-frequency variability modes. J. Climate, 28 (11), $4545-4560$

Washington R., James R., Pearce H., Pokam W., and Moufouma-Okia W. (2013). Congo Basin rainfall climatology: Can we believe the climate models? Phil. Trans. R. Soc. B., 368 (1625), 20120296

Wheeler T. and von Braun J. (2013). Climate change impacts on global food security. Science, 341 (6145), 508-513. DOI: $10.1126 /$ science. 1239402

World Meteorological Organization [WMO]. (2014). Annex to the Implementation Plan of the Global Framework for Climate Services (GFCS): Observations and Monitoring

WMO (2008). Establishment and Designation of WMO Regional Climate Centres (RCCs). Updated Interim Guidance 12 June 2008. World Climate Applications and Services Division Climate Prediction and Adaptation Branch

World Bank Group [WBG] (2016). Climate Information Services Providers in Kenya. Agriculture global practice technical assistance paper, World Bank Group, Washington, DC

World Population Review. (2021). Cameroon Population 2021 (Demographics, Maps, Graphs). [online] Available at: https://worldpopulationreview.com/ countries/cameroon-population 